\title{
Expansão recente do ensino superior brasileiro: (novos) elos entre educação, juventudes, trabalho?
}

Fabiana Augusta Alves Jardim Universidade de São Paulo (USP)

\author{
Wilson Mesquita de Almeida \\ Universidade Federal do ABC (UFABC)
}

Procuramos investigar a expansão recente do ensino superior brasileiro, delineando suas características gerais para compreender a nova configuração desse nível de ensino e suas articulações com o mercado de trabalho, também intensamente modificado nas duas últimas décadas. No contexto geral das transformações nas políticas públicas brasileiras e nas dinâmicas das desigualdades socioeconômicas, o esforço em mapear a articulação entre ensino superior e trabalho nos permite passar ao exame de algumas trajetórias juvenis de estudantes das camadas populares, no ensino público e no ensino privado, desdobrando consequências sobre o campo de possibilidades que estrutura a experiência juvenil hoje.

Palavras-chave: Educação. Democratização escolar. Juventude. Ensino superior. Trabalho. 


\section{Are there new nexus between school, youth and work? Perspectives from the recent expansion of higher education system in Brazil}

We investigate the recent process of expansion of Brazilian higher education level in the last two decades aiming to understand the new forms that it has assumed as well as its relations to labor market (that has changed intensely within this period of time). Considering the general context of transformation both in Brazilian public policies and their effects on socioeconomic inequalities, our effort is to map the new links between higher level education and work. We move on to examine the trajectories of young social disadvantaged students, both in public and for-profit institutions, unfolding consequences to understand the field of possibilities that structures youth experience nowadays.

Keywords: Education. Mass higher education. Youth. Work.

\section{Expansión reciente del sistema de educación terciária en Brasil: ¿(nuevos) eslabones entre educación, juventude y trabajo?}

Buscamos investigar la expansion reciente de la educación terciaria brasileña, presentando sus características generales, para comprender sus nuevas configuraciones y sus articulaciones con el mercado de trabajo (que ha sufrido intensos cambios en las dos últimas décadas). Tendo en cuenta las transformaciones en las políticas públicas brasileñas, el esfuerzo de mapear la articulación entre la educación terciaria y el trabajo permite examinar trayectórias de estudiantes de sectores populares, en la educación pública y privada, para de ahi apuntar consequencias sobre el campo de posibilidades que estructura la experiencia juvenil en la actualidad.

Palavras clave: Educación. Masificación de la educación. Juventud. Educación terciaria. Trabajo. 


\section{Apresentação}

[...] é perfeitamente cabível afirmar que, hoje, mesmo o adolescente ou o adulto analfabeto têm algumas possibilidades reais de ingressar no ensino comum, no Mobral, e caminhar ao longo da escolaridade até a obtenção de um diploma do ensino superior (BEISIEGEL, 1986).

A epígrafe que abre este artigo foi escolhida porque registra o valor positivo de que se revestia a universalização da educação básica e a expansão crescente de vagas nos ensinos médio e superior: na tendência à democratização, pela via da retirada de barreiras formais e da ampliação das vagas, tratava-se ao mesmo tempo de cuidar do futuro e de resgatar o passado, isto é, de garantir a educação das novas gerações, cuidando ainda de oferecer modalidades de ensino que atendessem às necessidades de jovens e adultos que não tiveram acesso à escolaridade regular.

Devido a nosso conhecimento empírico a respeito das condições de oferta dessa educação extemporânea, talvez a esperança depositada nesse movimento pareça excessivamente otimista. Mas, se nos lembrarmos da advertência feita por T. H. Marshall, em 1948, no que diz respeito aos efeitos da afirmação da educação como direito social e de sua democratização para a dupla garantia do direito do cidadão a ter sido educado (MARSHALL, 1978, p. 73) e do direito individual à igualdade de oportunidades, algum otimismo se justifica.

No contexto brasileiro, é bastante significativo que o processo tardio de democratização da educação tenha procurado afirmar o status de cidadania daquelas parcelas da população que até então não tinham logrado, pela falta de oferta de vagas ou de condições de permanência, acessar a educação escolar formal. Ainda que o alcance efetivo de tais medidas tenha sido limitado, elas foram simbolicamente importantes para sinalizar a disposição geral do sistema escolar no acolhimento das camadas populares. Que esse acolhimento tenha sido contraditório e dado origem a uma série de novas distinções é parte das reflexões que aqui intentamos realizar.

O foco deste artigo está em pensar as novas articulações entre educação, juventudes das camadas populares e trabalho que se delinearam nos últimos 20 anos. Trata-se de período intenso do ponto de vista das transformações no sistema de educação, em especial no ensino superior, mas também de mudanças profundas no mercado de trabalho, e ambas as esferas têm consequências sobre as experiências juvenis - as possibilidades que se abrem (ou se fecham); as trajetórias, escolares e de trabalho, praticáveis, à semelhança ou à diferença das dos pais; a experiência, portanto, de cidadania que se configura no interior dessas novas dinâmicas e seus efeitos sobre a estratificação social.

Iniciamos com a apresentação do histórico do ensino superior no Brasil, em sua relação com a democratização tardia da educação escolar no país e procurando 
compreender o movimento recente de expansão de vagas no contexto mais geral das reformas de Estado. Em seguida, procuramos caracterizar dois processos coetâneos à rápida expansão das vagas no ensino superior: as transformações na estrutura ocupacional, examinando o tipo de postos de trabalho criados no recente ciclo de crescimento econômico e a tendência, que caracterizou especialmente os últimos dez anos, de diminuição das desigualdades econômicas no Brasil. Ambos os processos guardam relação, complexa, com a demanda de acesso ao ensino superior e com os "padrões de uso" desse nível de ensino. Na terceira seção, levantamos novos desafios a partir de literatura que examina as trajetórias juvenis de estudantes das camadas populares, no ensino superior público e no ensino superior privado. Nas considerações finais comentamos os efeitos das políticas recentes de expansão no ensino superior, sugerindo que elas participam do processo mais geral de alteração no padrão das desigualdades brasileiras, resultando em um processo contraditório de expansão de direitos formais pela via da (re)mercadorização de alguns setores, mas limitando seus possíveis efeitos sobre a estratificação social.

\section{Ensino superior no Brasil: breve apresentação de sua trajetória}

Inexistente no país até 1808 , isto é, até a vinda da Família Real e da Corte Portuguesa para o Rio de Janeiro, foi durante o período imperial que se estruturaram duas vias em direção ao ensino superior: por meio do Colégio Pedro II, fundado em 1837, no qual funcionava o ensino secundário regular, criado pelo poder central, e por meio de exames preparatórios, oferecidos pela iniciativa privada nas províncias (SANTOS, 1998, p. 241). Como bem demonstrou Hilsdorf (2006), o Império promoveu uma falsa descentralização do ensino secundário, pois exerceu forte controle sobre a demanda por cursos superiores ao somente permitir o acesso direto às Academias àqueles que frequentassem o ginásio oficial. Sem a equivalência da certificação oferecida por seus estabelecimentos ao colégio da Corte, a consequência foi que as províncias abandonaram o ensino secundário e incentivaram o crescimento dos cursos parcelados ou preparatórios.

$\mathrm{Na}$ transição da Monarquia para o Regime Republicano ocorreram mudanças políticas significativas, com efeitos para a educação em geral e, mais importante para nossa discussão, para o acesso à educação superior. A partir de 1911, uma série de reformas na legislação educacional introduziu lógicas seletivas que estão na raiz dos processos seletivos que operam a fronteira entre o atual ensino médio e o ensino superior. ${ }^{1}$ Mais precisamente, na Reforma de 1915 , os exames de admissão

1 Asreformas educacionais a que nos referimos são: Reforma Rivadávia Corrêa(1911); Reforma Carlos Maximiliano (1915) e Reforma Rocha Vaz (1925). Conforme Lima, Silva e Silva (2002). 
às escolas superiores receberam a denominação de exames vestibulares, consistindo em rigorosa prova escrita e oral. Se nos lembrarmos de que a estrutura de ensino até então já operava sua seletividade no exame de admissão na passagem ao ginásio, podemos perceber o alto grau de elitização no ensino superior naquele momento.

A exemplo de outras políticas sociais, somente após 1930 o desafio de expansão das vagas educacionais foi enfrentado, participando do processo mais geral de constituição de um sistema de proteção social no país (DRAIBE, 1993). Assim, a partir do governo de Getúlio Vargas, inicia-se uma rápida (ainda que insuficiente, frente à demanda reprimida por tantos anos) expansão na abertura de vagas e de matrículas em todos os níveis de ensino (BEISIEGEL, 1986).

No contexto internacional, a partir dos anos 1940, os sistemas de ensino nos países ocidentais ganharam novo impulso na direção da massificação. Como indica Troger:

[...] É, portanto, uma inversão da lógica até então dominante que simboliza a "democratização do ensino": a escola é cada vez mais percebida como uma oportunidade para todas as crianças, e não somente para uma elite, de ascender a uma posição social melhor que a de seus pais (TROGER, 2012, p. 16-17).

Schofer e Meyer (2005, p. 903) destacam alguns fatores institucionais responsáveis por essa mutação: liberalização e expansão dos direitos humanos, o fortalecimento da ciência, a ascensão de doutrinas e ideários de desenvolvimento nacional como o keynesianismo e a estruturação de organizações internacionais que promoveram discursos e modelos em prol da educação, como a Organização das Nações Unidas para a Educação, a Ciência e a Cultura (Unesco).

Entre nós, as mudanças nas taxas de escolarização de nível superior começam a ganhar consistência a partir da década de 1960, com a aprovação da Lei de Diretrizes e Bases da Educação Nacional (LDB) de 1961, pois ali se estabelece a equivalência de todos os cursos do ensino médio para efeito de candidatura ao ensino superior, o que imediatamente habilita um novo contingente: agora, serão postulantes, além do secundário (até então a via natural), os egressos de cursos médios industrial, comercial, agrícola e o normal. Os efeitos são velozes: "[...] o total de universitários em todo o país no ano de 1950 era de 46 mil e passou a 93 mil em 1960. Já em 1970 havia 425 mil estudantes matriculados[;] em 1977, as matrículas atingem a cifra de 1 milhão" (OLIVEN, 1993, p. 75). É também nesse momento que toma vulto o problema da demanda superior à oferta, configurando um dos pontos de "estrangulamento" do sistema de ensino - além disso, atingindo jovens, plenamente capazes de reivindicação e afetados pelo clima intelectual e social do final dos anos 1960, o que representava um risco político. A medida tomada em relação a esse aspecto veio com o Decreto $n^{\circ}$ 68.908/1971, que instituiu o vestibular classificatório.

A Reforma Universitária de 1968, durante o regime de exceção, constituiu um divisor para a compreensão da gênese e atual domínio do setor privado lucrativo no ensino 
superior brasileiro. A partir dela, houve uma expansão limitada da rede pública federal, cujas vagas foram ocupadas pelos segmentos médios mais dotados de capital econômico e cultural. Tal característica foi reforçada pelo fato de o setor público ter se voltado mais detidamente para a pós-graduação, no intuito da formação de professores em nível superior e do desenvolvimento do setor de Ciência, Tecnologia e Inovação (CT\&I) no país. Em face da retração da participação do setor público de ensino superior e do setor confessional (vinculado às instituições religiosas), concomitantemente houve a emergência e o crescimento de um novo tipo de setor privado. Um olhar para a história revela que até a década de 1970, o setor voltado para auferir lucros com a venda de serviços educacionais em nível superior - hoje hegemônico - era ínfimo (tabela 1).

\section{TABELA 1}

EVOLUÇÃO DO NÚMERO DE INSTITUIÇÕES POR NATUREZA E DEPENDÊNCIA ADMINISTRATIVA: BRASIL (1980-1995)

\begin{tabular}{|c|c|c|c|c|c|c|c|c|c|c|c|c|c|c|c|}
\hline \multirow[b]{2}{*}{$\frac{0}{\frac{1}{4}}$} & \multirow[b]{2}{*}{$\begin{array}{l}\bar{\pi} \\
\overline{0} \\
0 \\
\overline{0} \\
0 \\
0 \\
0\end{array}$} & \multicolumn{5}{|c|}{ Universidades } & \multicolumn{4}{|c|}{$\begin{array}{l}\text { Faculdades } \\
\text { integradas e centros } \\
\text { universitários }\end{array}$} & \multicolumn{5}{|c|}{ Estabelecimentos isolados } \\
\hline & & 营 & $\begin{array}{l}\overline{0} \\
\frac{\pi}{0} \\
\stackrel{0}{0} \\
\stackrel{4}{0}\end{array}$ & 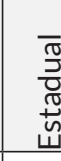 & 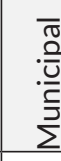 & $\begin{array}{l}\frac{\pi}{0} \\
\stackrel{2}{2} \\
2 \\
\end{array}$ & $\begin{array}{l}\bar{\pi} \\
\stackrel{\sqrt[\pi]{0}}{\rho}\end{array}$ & $\begin{array}{l}\bar{\sigma} \\
\frac{0}{0} \\
\tilde{J} \\
\tilde{U}\end{array}$ & $\begin{array}{l}\bar{\pi} \\
. \frac{\Omega}{U} \\
. \frac{1}{\Sigma} \\
\Sigma\end{array}$ & $\begin{array}{l}\frac{\pi}{0} \\
\frac{\pi}{2} \\
: 2 \\
0\end{array}$ & 㔄 & $\begin{array}{l}\bar{\pi} \\
\frac{\pi}{0} \\
\frac{d}{d} \\
\stackrel{4}{4}\end{array}$ & 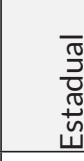 & 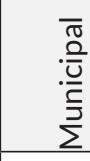 & 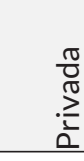 \\
\hline 1980 & 882 & 65 & 34 & 9 & 2 & 20 & 20 & 1 & - & 19 & 797 & 22 & 43 & 89 & 643 \\
\hline 1981 & 876 & 65 & 34 & 9 & 2 & 20 & 49 & 1 & 1 & 47 & 762 & 18 & 68 & 126 & 550 \\
\hline 1982 & 873 & 67 & 35 & 10 & 2 & 20 & 51 & - & 2 & 49 & 755 & 18 & 70 & 122 & 545 \\
\hline 1983 & 861 & 67 & 35 & 10 & 2 & 20 & 57 & - & 1 & 56 & 737 & 18 & 69 & 111 & 539 \\
\hline 1984 & 847 & 67 & 35 & 10 & 2 & 20 & 59 & - & 1 & 58 & 721 & 18 & 64 & 108 & 531 \\
\hline 1985 & 859 & 68 & 35 & 11 & 2 & 20 & 59 & - & 1 & 58 & 732 & 18 & 64 & 102 & 548 \\
\hline 1986 & 855 & 76 & 35 & 11 & 3 & 27 & 65 & - & 2 & 63 & 714 & 18 & 79 & 115 & 502 \\
\hline 1987 & 853 & 82 & 35 & 14 & 4 & 29 & 66 & - & - & 66 & 705 & 19 & 69 & 99 & 518 \\
\hline 1988 & 871 & 83 & 35 & 15 & 2 & 31 & 67 & - & 1 & 66 & 721 & 19 & 72 & 89 & 541 \\
\hline 1989 & 902 & 93 & 35 & 16 & 3 & 39 & 64 & - & - & 64 & 745 & 19 & 68 & 79 & 579 \\
\hline 1990 & 918 & 95 & 36 & 16 & 3 & 40 & 74 & - & - & 74 & 749 & 19 & 67 & 81 & 582 \\
\hline 1991 & 893 & 99 & 37 & 19 & 3 & 40 & 85 & - & 3 & 82 & 709 & 19 & 63 & 78 & 549 \\
\hline 1992 & 893 & 106 & 37 & 19 & 4 & 46 & 84 & - & 3 & 81 & 703 & 20 & 63 & 81 & 539 \\
\hline 1993 & 873 & 114 & 37 & 20 & 4 & 53 & 88 & - & 3 & 85 & 671 & 20 & 57 & 80 & 514 \\
\hline 1994 & 851 & 127 & 39 & 25 & 4 & 59 & 87 & - & 3 & 84 & 637 & 18 & 48 & 81 & 490 \\
\hline 1995 & 894 & 135 & 39 & 27 & 6 & 63 & 111 & 5 & 5 & 101 & 648 & 18 & 44 & 66 & 520 \\
\hline
\end{tabular}

Fonte: Inep, MEC e Seep

A partir da década de 1970 ocorre o decréscimo na participação pública no total das matrículas. Além da não expansão do setor público federal e do setor privado 
confessional durante o Regime Militar, desenvolveram-se estímulos para a gênese e expansão do setor empresarial no ensino superior brasileiro (tabela 2). O ponto a salientar é que o aparato estatal do período não só se omitiu - deixando de ampliar o acesso via instituição pública ou propor alternativas -, mas teve papel ativo ao conceder incentivos e subvenções prescritas na Constituição ${ }^{2}$ e, também, mediante a interferência do órgão central responsável pela autorização de abertura dos cursos em prol do segmento lucrativo: o Conselho Federal de Educação (GOUVEIA, 1968; CUNHA, 1975; SAMPAIO, 2000; DURHAM, 2003; MARTINS, 2009; ALMEIDA, 2014).

\section{TABELA 2}

Evolução da Matrícula por Dependência Administrativa (1980-1995)

\begin{tabular}{|c|c|c|c|c|c|c|}
\hline Ano & Total & Federal & Estadual & Municipal & Privada & $\begin{array}{l}\text { Matrículas } \\
\text { nas } \\
\text { Instituições } \\
\text { de Ensino } \\
\text { Superior } \\
\text { (IES) } \\
\text { privadas }\end{array}$ \\
\hline 1980 & 1.377 .286 & 316.715 & 109.252 & 66.265 & 885.054 & $64,2 \%$ \\
\hline 1981 & 1.386 .792 & 313.217 & 129.659 & 92.934 & 850.982 & $61,3 \%$ \\
\hline 1982 & 1.407 .987 & 316.940 & 134.901 & 96.547 & 859.599 & $61 \%$ \\
\hline 1983 & 1.438 .992 & 340.118 & 147.197 & 89.374 & 862.303 & $59,9 \%$ \\
\hline 1984 & 1.399 .539 & 326.199 & 156.013 & 89.667 & 827.660 & $59,1 \%$ \\
\hline 1985 & 1.367 .609 & 326.522 & 146.816 & 83.342 & 810.929 & $59,2 \%$ \\
\hline 1986 & 1.418 .196 & 325.734 & 153.789 & 98.109 & 840.564 & $59,2 \%$ \\
\hline 1987 & 1.470 .555 & 329.423 & 168.039 & 87.503 & 885.590 & 60,2 \\
\hline 1988 & 1.503 .555 & 317.831 & 190.736 & 76.784 & 918.204 & $61 \%$ \\
\hline 1989 & 1.518 .904 & 315.283 & 193.697 & 75.434 & 934.490 & $61,5 \%$ \\
\hline 1990 & 1.540 .080 & 308.867 & 194.417 & 75.341 & 961.455 & $62,4 \%$ \\
\hline 1991 & 1.565 .056 & 320.135 & 202.315 & 83.286 & 959.320 & $61,2 \%$ \\
\hline 1992 & 1.535 .788 & 325.884 & 210.133 & 93.645 & 906.126 & $59 \%$ \\
\hline 1993 & 1.594 .668 & 344.387 & 216.535 & 92.594 & 941.152 & $59 \%$ \\
\hline 1994 & 1.661 .034 & 363.543 & 231.936 & 94.971 & 970.584 & $58,4 \%$ \\
\hline 1995 & 1.759 .703 & 367.531 & 239.215 & 93.794 & 1.059 .163 & $60,1 \%$ \\
\hline
\end{tabular}

Fonte: Inep, MEC e Seep.

Vale ainda destacar que os anos 1980 foram marcados por sucessivas crises econômicas, inflação alta e altas taxas de desemprego. Mesmo com relativa

$2 \mathrm{Na}$ época, crédito educativo e isenções fiscais. Tais estímulos, reformulados, permaneceram e foram ampliados nos governos democráticos subsequentes, consolidando a oferta de vagas na graduação brasileira pelo setor privado lucrativo. 
estagnação das matrículas e oscilações ao longo dos anos, o setor privado lucrativo logrou manter a média de sua participação, ainda que as condições das famílias e dos trabalhadores para investir no ensino superior deteriorassem.

Temos, assim, uma trajetória de estruturação do nível superior do ensino no país que é marcada pela elitização até o final da década de 1960 e, a partir daí, é dinamizada pela flexibilização das regras para oferta privada de ensino, o que configura prática estatal de mercadorização da educação, na medida em que o Estado estimula, indiretamente, o crescimento do setor privado. Esping-Andersen (2006), após exame comparado de diversos países (todos desenvolvidos), constrói uma tipologia em que associa o padrão de proteção ao grau de liberdade que o cidadão tem em relação à família (origem social), ao mercado e ao próprio Estado. É assim que cunha o termo desmercadorização, para avaliar o grau de interferência estatal na formação dos mercados para provisão de serviços essenciais (saúde, educação, previdência etc.), bem como a interferência na estratificação social. Quanto maior o grau de desmercadorização, maior o grau de liberdade individual em relação à origem social, maior a possibilidade de contar com os serviços estatais e menos submetido às diferenciações mercadológicas um cidadão estará; em sentido contrário, quanto menor o grau de desmercadorização, maior a dependência em relação à origem social, menores a chance de poder (ou querer) contar com serviços estatais - além disso, estigmatizantes, pois que desenhados para atender somente os mais pobres -, e maior a segmentação do mercado de serviços ao qual o cidadão terá que acorrer, o que significa que a qualidade do serviço será inteiramente dependente de seu poder de compra. Retomamos aqui tal contribuição porque ela nos parece bastante útil para compreender os efeitos da introdução da lógica privatizante, e também para compreender alguns dos dilemas da democratização do ensino superior forjados nas duas últimas décadas.

\section{A expansão recente do ensino superior no Brasil (1995-2015) e seus dilemas}

\section{Educação superior entre 1995 e 2002}

A política educacional de ensino superior do governo Fernando Henrique Cardoso (FHC) (1995-2002) partia da premissa de que era preciso, imperiosamente, expandir o sistema. As ideias básicas eram estimular a concorrência interna no setor privado e, mediante o recurso da avaliação dos alunos via exame nacional - na época, o Exame Nacional de Cursos, apelidado de Provão ${ }^{3}$ - e das condiç̧̃es de ensino da instituição,

3 Hoje o Exame Nacional de Desempenho de Estudantes (Enade). 
garantir o controle da qualidade da educação superior ofertada. Para o incentivo à concorrência, novos atores competitivos foram pensados como essenciais. Tal pensamento materializou-se por meio do Decreto $n^{\circ} 2.306 / 1997$, na figura dos centros universitários, os quais foram dotados de autonomia para abrir e fechar cursos. Essas novas instituições tiveram um crescimento significativo no período (tabela 3).

\section{TABELA 3}

Evolução das INSTITUIÇÕES DE ENSINO SUPERIOR (IES) no Brasil, por organização acadêmica (19962005)

\begin{tabular}{l|l|l|l|l|l}
\hline Ano & Universidades & $\begin{array}{l}\text { Centros } \\
\text { universitários }\end{array}$ & $\begin{array}{l}\text { Faculdades } \\
\text { integradas }\end{array}$ & $\begin{array}{l}\text { Faculdades, } \\
\text { escolase } \\
\text { institutos }\end{array}$ & $\begin{array}{l}\text { Centros de } \\
\text { educação } \\
\text { tecnológica } \\
\text { efaculdades } \\
\text { de } \\
\text { tecnologia }\end{array}$ \\
\hline 1996 & 138 & 0 & 143 & 643 & 0 \\
\hline 1997 & 150 & 13 & 78 & 659 & 0 \\
\hline 1998 & 153 & 18 & 75 & 727 & 0 \\
\hline 1999 & 155 & 39 & 74 & 813 & 16 \\
\hline 2000 & 156 & 50 & 90 & 865 & 19 \\
\hline 2001 & 156 & 60 & 99 & 1.036 & 34 \\
\hline 2003 & 162 & 77 & 105 & 1.240 & 53 \\
\hline 2004 & 169 & 81 & 119 & 1.03 & 93 \\
\hline 2005 & 176 & 107 & 119 & 1.474 & 144 \\
\hline
\end{tabular}

Fonte: MEC, Inep e Deaes.

Ao lado da flexibilização, houve uma aposta na avaliação como mola mestra de toda a política educacional: ela seria o mecanismo eficaz para conter uma possível expansão danosa da graduação privada lucrativa. Analisando os fatos ocorridos, no entanto, os rumos tomados foram outros, bem diferentes do planejado. Do ponto de vista da esperada competição salutar (SOUZA, 2005, P. 179), houve, objetivamente, batalhas calcadas em uma guerra de preços das mensalidades entre universidades tradicionais e os novos competidores, muito deles centros universitários que, depois, pleitearam o título de universidades. No que tange à avaliação como remédio eficaz para garantir a qualidade do ensino superior privado lucrativo, ela provocou alguns impactos em um segmento acostumado a obter somente benesses. Porém, toda a questão reside na efetividade de tais políticas avaliativas, manipuláveis uma vez que a regras estejam definidas e sem efeito devido aos prazos largos e das protelações obtidas via liminares judiciais pelas instituições privadas em falta com o que dispõe o Estado. Em vez de um setor privado diversificado, com novos atores competitivos, controlado por meio de avaliações nacionais, houve a preparação do terreno para a fase de emergência de grandes grupos educacionais e fundos de investimentos, a partir de 2005. 


\section{Expansão do ensino superior entre 2003 e 2015}

A gestão de Luiz Inácio Lula da Silva, em 2003, recebe tal herança institucional, longamente gestada. O período é marcado por reformas estatais na direção da universalização de direitos sociais e pela introdução de políticas integradas de redistribuição de renda. A despeito da tendência à redução das desigualdades econômicas, é um tempo de diversas contradições, articuladas em um arranjo governamental que tem sido nomeado como lulismo ou pós-neoliberalismo, e cujas práticas foram adotadas também em diversos países latino-americanos (SINGER, 2012).

O dinamismo econômico, a geração de postos de trabalho formais (como examinaremos na próxima seção), os efeitos da universalização do ensino fundamental (e também de suas desigualdades em termos de qualidade) ${ }^{4}$ e da expansão das vagas no ensino médio, todos esses fatores alteram as pressões pelo acesso ao ensino superior. Além disso, a consolidação democrática traz novas demandas para a arena política, permitindo, por exemplo, a formulação do problema político do racismo brasileiro, sistematicamente negado ao longo de nossa história (GUIMARÃES, 2012).

\section{TABELA 4}

Número de IES por Organização Acadêmica e Categoria Administrativa: Brasil (2003-2013)

\begin{tabular}{|c|c|c|c|c|c|c|c|c|c|}
\hline \multirow{3}{*}{ Ano } & \multicolumn{9}{|c|}{ Instituições } \\
\hline & \multirow{2}{*}{ Total } & \multicolumn{2}{|c|}{ Universidade } & \multicolumn{2}{|c|}{$\begin{array}{l}\text { Centro } \\
\text { universitário }\end{array}$} & \multicolumn{2}{|c|}{ Faculdade } & \multicolumn{2}{|c|}{ IF e Cefet } \\
\hline & & Pública & Privada & Pública & Privada & Pública & Privada & Pública & Privada \\
\hline 2003 & 1.859 & 79 & 84 & 3 & 78 & 86 & 1.490 & 39 & - \\
\hline 2004 & 2.013 & 83 & 86 & 3 & 104 & 104 & 1.599 & 34 & - \\
\hline 2005 & 2.165 & 90 & 86 & 3 & 111 & 105 & 1.737 & 33 & - \\
\hline 2006 & 2.270 & 92 & 86 & 4 & 115 & 119 & 1.821 & 33 & - \\
\hline 2007 & 2.281 & 96 & 87 & 4 & 116 & 116 & 1.829 & 33 & - \\
\hline 2008 & 2.252 & 97 & 86 & 5 & 119 & 100 & 1.811 & 34 & - \\
\hline 2009 & 2.314 & 100 & 86 & 7 & 120 & 103 & 1.863 & 35 & - \\
\hline 2010 & 2.378 & 101 & 89 & 7 & 119 & 133 & 1.892 & 37 & - \\
\hline 2011 & 2.365 & 102 & 88 & 7 & 124 & 135 & 1.869 & 40 & - \\
\hline 2012 & 2.416 & 108 & 85 & 10 & 129 & 146 & 1.898 & 40 & - \\
\hline 2013 & 2.391 & 111 & 84 & 10 & 130 & 140 & 1.876 & 40 & - \\
\hline
\end{tabular}

Fonte: MEC e Inep.

4 Ver Oliveira (2007). 
No que se refere ao ensino superior, a já referida tabela 3 e a tabela 4 revelam que a flexibilização introduzida no momento anterior estancou a expansão das vagas no setor privado a partir da criação de universidades: enquanto as públicas aumentaram $40,5 \%$, as privadas tiveram estabilidade. O mesmo não ocorre nas outras formas de organização: os centros universitários privados aumentam $66,6 \%$, e as faculdades, $25 \%$, enquanto os públicos aumentaram, respectivamente, $230 \%$ e $62,5 \%$. Assim, embora o ritmo de crescimento das instituições públicas tenha sido superior em todas as categorias de organização acadêmica, é importante destacar que - devido à dependência da trajetória ${ }^{5}$ - o setor privado aumenta sua participação no sistema de ensino e termina o período concentrando 87,4\% das instituições.

Assim, no governo Lula, o setor privado lucrativo já começa a ganhar uma nova configuração, na qual o capital internacional entra no mercado brasileiro de ensino superior. A rigor, a entrada dos fundos de investimentos na área da educação superior privada, no Brasil, iniciou-se em 2001, com uma parceria entre a Apollo Internacional, empresa voltada para investimentos estrangeiros do Apollo Group (maior grupo empresarial de ensino dos Estados Unidos), e o Pitágoras, de Minas Gerais, criado em 1966 pelo professor Walfrido dos Mares Guia - que viria a ser ministro na gestão Lula por duas vezes, na pasta do Turismo e depois na pasta das Relações Institucionais (ROSENBURG, 2002, p. 35).

Concluímos que a grande expansão do ensino superior privado lucrativo teve como consequência, já no contexto de desemprego e baixo crescimento econômico do segundo governo FHC, a sobra de vagas não preenchidas, inadimplência e evasão, tornando a busca pelo crédito ou alívio de impostos o objetivo maior das universidades privadas. Nesse bojo, surge o Programa Universidade para Todos (ProUni), implementado em 2005 pelo governo de Luiz Inácio Lula da Silva, com o objetivo de conceder bolsas de estudos integrais (100\%) e parciais (25\% a 50\%) a estudantes de baixa renda em cursos de graduação de instituições particulares em troca de isenções fiscais. Entre o Projeto de Lei $n^{\circ}$ 3.582/2004 e a redação definitiva da Lei $n^{\circ} 11.096 / 2005$, que instituiu o programa, houve mudanças decorrentes das interferências do segmento privado lucrativo. Tamanha influência dos interesses privados pode ser constatada a partir do total de emendas propostas pelos deputados, em sua grande maioria com claro interesse das mantenedoras: o Projeto de Lei recebeu 292 propostas de emenda (CATANI; GILIOLI, 2005, p. 58). No que tange ao Fundo de Financiamento Estudantil (Fies), o então presidente Luiz Inácio Lula da Silva sancionou a lei que reformulou as regras desse fundo de financiamento (Lei $n^{\circ} 11.552$, de 2007), permitindo ao Fies financiar até $100 \%$ da mensalidade - antes o limite era 70\%. Atualmente, já no governo Dilma, as condições

5 Para uma revisão bibliográfica sobre o tema, ver Bernardi (2012). 
foram ainda mais ampliadas, com maior prazo de carência para pagamento, além de taxas bem menores de juros - chegando a cerca de 3\% ao ano (a.a.). Dados do próprio Ministério da Educação (MEC) apontam a transferência de recursos públicos da ordem de $R$ \$13,7 bilhões para o orçamento do Fies em 2014, os quais permitiram que as universidades mais bem-dotadas financeiramente - já que sob tutela de fundos de investimentos e com ações nas Bolsas de Valores - pudessem se transformar nos conglomerados com o maior número de alunos do mundo. Foi preciso o ajuste recente das contas públicas para mexer, ainda que de forma tímida, com tais incentivos.

O governo Lula e o atual governo Dilma, por meio do ProUni e do Fies, mantiveram o financiamento público indireto ao segmento privado com fins lucrativos no campo da educação superior iniciado durante o Regime Militar e alimentado vigorosamente durante o governo FHC. Desta forma, as ações trazem, em sua própria estrutura, elementos velhos - a sustentação da hegemonia na graduação brasileira do modelo privado lucrativo; emergentes - permitindo uma tímida e fraca regulação dos benefícios dados a esse mesmo setor; e elementos de avanços - ligados à inclusão no ensino superior brasileiro de estudantes ligados às frações da classe média baixa e de baixa renda, negros, de mais idade e das periferias das grandes cidades brasileiras.

\section{Outras desigualdades: transformações recentes no mercado de trabalho}

Tratamos até aqui das mudanças na estrutura do ensino superior brasileiro do ponto de vista de sua dinâmica interna, o que nos levou a examinar de modo mais insistente a expansão da oferta de vagas e seus novos efeitos para a desigualdade de chances de acesso a este nível de ensino. Nesta seção nos dedicaremos a analisar o mundo do trabalho, frequentemente associado - no senso comum e na política - à esfera educacional. Como já mencionamos, tal imbricamento foi forjado historicamente e se consolidou após o final da Segunda Guerra Mundial, vinculandose ainda à dimensão do desenvolvimento econômico (e, mais recentemente, ao desenvolvimento humano) de um país.

De partida, vale notar que a associação entre educação escolar e rendimentos do trabalho assumiu configurações muito distintas, a depender dos contextos nacionais, justamente porque os ritmos da massificação escolar variam em relação às forças sociais, à estrutura produtiva, à constituição estatal, entre outros fatores (LOURENÇO FILHO, 2004). Da mesma maneira, variam as formas dos sistemas escolares, seu grau de vinculação com a estrutura ocupacional e, portanto, seus efeitos sobre a estratificação social. 
As duas últimas décadas foram marcadas por situações extremas no que diz respeito ao mercado de trabalho: experimentamos desde uma crise econômica profunda, que levou a altas taxas de desemprego, até um período de crescimento econômico e reversão na tendência à diminuição do contingente de trabalhadores ocupados em setores informais (IPEA, 2007; SABOIA, 2014).

O processo é, de novo, contraditório: se é verdadeiro que os empregos criados a partir da metade da década de 2000 são mais protegidos, também é verdade que do ponto de vista da remuneração e do setor de atividades em que tais postos de trabalho são criados, eles se distanciam do conjunto de direitos e valores associados ao trabalho assalariado formal (SABOIA, 2014; GUIMARÃES, 2013). Se as altas taxas de desemprego que caracterizaram os anos em torno da virada do século atingiam majoritariamente os jovens, sempre sobrerrepresentados entre os desempregados em procura e aqueles em desemprego oculto pelo desalento (JARDIM, 2009), é certamente positivo que eles cheguem ao mercado de trabalho em momento de abertura e expansão de vagas; mas há que se ter em conta os circuitos do mercado de trabalho por onde eles - variando sua escolaridade e seu capital social - logram circular (GUIMARÃES, 2013), pois tais experiências, de procura e de trabalho, certamente têm efeitos para a conformação das expectativas e demandas em relação à escolarização, em geral, e ao ensino superior.

Analisando dados a respeito da dinâmica do mercado de trabalho no que se refere à presença de mão de obra qualificada em cursos de ensino superior, Comin e Barbosa (2011) encontram que a recente expansão das vagas no ensino superior não levou, conforme o modelo que associa qualificação e postos de trabalho, a uma inserção qualificada dos trabalhadores, agora diplomados. Os dados mobilizados pelos autores demonstram o aumento de trabalhadores graduados em nível superior em todos os grandes grupos ocupacionais (COMIN; BARBOSA, 2011, p. 80), inclusive (e de forma mais acelerada) no grupo das ocupações elementares:

[...] Enquanto a ocupação como um todo cresceu cerca de 65\%, o número de graduados aumentou mais de 15 vezes [nesse grupo]. Obviamente, estamos tratando de fenômenos com proporções muito diversas. Enquanto, em 2009, pouco mais de 7 milhões de indivíduos faziam parte do GG2 (e desses, quase 5 milhões eram graduados), o GG9 era composto de mais de 32 milhões de pessoas (cerca de 510 mil sendo graduadas). Logo, os graduados estão empregados, em sua maioria, em grupos ocupacionais que tradicionalmente formam seu principal nicho. Mas chama a atenção a velocidade (em aceleração) com que cresce o número de pessoas com ensino superior em ocupações que formalmente não requerem mais do que o ensino médio ou apenas o fundamental (COMIN; BARBOSA, 2011, p. 8384; grifos próprios).

Como os autores sugerem, trata-se de trabalhadores que, tendo concluído o ensino médio (ou mesmo tendo retornado já adultos aos bancos escolares para conclui-lo) hoje se veem em condições de aproveitar as conjunturas econômica e educacional 
favoráveis, vendo aí uma oportunidade de incremento de sua posição no mercado de trabalho. É por essa razão que os autores reiteram que sua análise esclarece "[...] a 'origem' social dos novos graduados e não seu 'destino' ocupacional" (COMIN; BARBOSA, 2011, p. 85). São, majoritariamente, trabalhadores que estudam - para inverter a tradicional concepção em relação aos estudantes de cursos noturnos, nos diferentes níveis de ensino, que os pensa como "alunos-trabalhadores".

Outro aspecto importante abordado por Comin e Barbosa refere-se à observação de que os ganhos reais do salário mínimo e a expansão do trabalho assalariado formal - que chega a 2013 abrangendo 55\% da População Economicamente Ativa (PEA) - foram fatores importantes para explicar a diminuição da imensa desigualdade de renda que conferia ganhos ("prêmio salarial") para cada ano de escolaridade. Apesar de o ensino superior ainda resultar em grande acréscimo de renda, "a elevação mais que proporcional da renda dos estratos inferiores" (COMIN; BARBOSA, 2011, p. 89) e, possivelmente, o próprio processo de expansão das vagas no ensino superior, reforçam a tendência geral de redução das desigualdades.

O trabalhador que estuda e que viu nos recentes programas de acesso ao ensino superior uma oportunidade, certamente tem preocupações e desafios distintos dos do estudante típico ideal. Abdal e Navarra (2014), por exemplo, abordam a questão articulando as desigualdades socioeconômicas à dinâmica das desigualdades socioespaciais na Região Metropolitana de São Paulo. Os autores trazem mais elementos para compreender a rápida expansão das instituições de ensino superior privado lucrativo, ao mostrar que seu sucesso deve-se também à sua capacidade (econômica) de fazer frente à especulação urbana: localizadas em regiões com fácil acesso de transporte público, centrais ou em saídas de metrô, as Instituições de Ensino Superior (IES) privadas atuam para reduzir os custos da educação, diminuindo gastos de dinheiro e de tempo nos deslocamentos urbanos - sempre muito custosos para os segmentos populares que, geralmente, vivem distantes do local de trabalho e empreendem verdadeiras epopeias diárias. Além de bastante perspicaz, a abordagem acaba por revelar uma profunda alteração simbólica no acesso ao ensino superior, na medida em que ele ocupa um lugar marginal na vida do estudante, que precisa fazer encaixar os estudos em sua rotina, escolhendo (cursos, instituições) por razões pragmáticas, em especial quando não tem capital escolar - mensurado pelo Exame Nacional do Ensino Médio (Enem), porta de entrada para o ProUni - que os qualifique a escolher as instituições ou os cursos mais prestigiados, pelos quais valeria a pena percorrer distâncias maiores em razão da qualidade do ensino e do valor do diploma (ABDAL; NAVARRA, 2011, p. 80).

A partir de contribuições como essas, compreendemos que, em grande medida, o público que acessa o ProUni é constituído por parcelas da população que têm sido reconhecidas como classe $C$, nova classe média, nova classe trabalhadora ou, ainda, batalhadores (SOUZA, 2012; KERSTENETZKY; UCHOA, 2013). Celebrada 
por sua potencialidade de consumo, há quem levante a hipótese de que os esforços de classificação nesses termos participam de um movimento mais estrutural de esvaziamento da potência propriamente política dos setores populares a partir dos anos 1990, quando os novos personagens deixam a cena na direção dos bastidores (das gestões públicas) e os jovens das periferias urbanas são confrontados com a necessidade de construir outras narrativas para dar sentido à sua experiência no bairro, na escola, na cidade, no trabalho (D'ANDREA, 2013).

\section{Os jovens das camadas populares nos labirintos do ensino superior}

As duas últimas décadas introduziram, portanto, mudanças nas políticas de acesso ao ensino superior voltadas, sobremaneira, para os segmentos socialmente mais desprovidos.

Tais mudanças se iniciaram na segunda metade dos anos 1990, período no qual ocorreram processos concomitantes de quase universalização do acesso à educação fundamental e uma acentuada expansão do ensino médio. Tais processos desencadearam incremento na demanda e na luta por vagas no ensino superior público por parte de setores da "classe média baixa" e de baixa renda, as quais ganhariam materialidade no início dos anos 2000 , com a adoção de cotas raciais e sociais em algumas universidades federais e estaduais brasileiras (MOEHLECKE, 2004; ALMEIDA, 2009). Porém, a grande mutação se dá com o uso em ampla escala do Enem como forma de acesso ao ensino superior, efetivado somente a partir de 2004 como seleção para o ProUni e, mais tarde, em 2010, com sua utilização também nas federais, por meio do Sistema de Seleção Unificado (SisU), permitindo a disputa pela vaga das universidades participantes a partir da nota do aluno naquele exame nacional. Com a Lei de Cotas, ${ }^{6}$ de 2012, aprofunda-se a institucionalização das ações afirmativas no ensino público federal. O fato é que a utilização do Enem como método seletivo para as vagas do ProUni e do sistema federal, acoplado às ações afirmativas, foi o "pulo do gato" das políticas de acesso à educação superior a partir do governo Lula. As frações de classe média baixa e de baixa renda que, conforme dito acima, lutavam por acesso, a partir do uso do Enem terão suas chances ampliadas, pois, agora, possuem mais oportunidades de ultrapassar a barreira da restrição competitiva no vestibular das universidades públicas.

Entretanto, cabe ponderar, tais mudanças nas políticas públicas de acesso não foram suficientes para alterar aspectos ainda estruturantes nas relações entre as frações de classe sociais brasileiras no que tange ao ingresso e à permanência no

6 Dispõe que 50\% das vagas dos cursos das universidades federais serão destinadas a alunos de baixa renda, oriundos da escola pública e, entre elas, vagas para estudantes negros e indígenas, proporcionais à sua presença na população de cada estado. 
ensino superior. Vários estudos empíricos percorreram as dificuldades de escrita e leitura das camadas populares na universidade (DAUSTER, 2003; PAVÃO, 2004); da apropriação de bolsas de iniciação científica (VILLAS BÔAS, 2001); as tensões surgidas no contato com estratos sociais mais favorecidos, criando situações em que emerge o preconceito de classe (DAUSTER, 2003), a "humilhação social" (BARBOSA, 2004) e o desenraizamento (SILVA, 2003). Outros procuraram verificar a entrada desses indivíduos de baixa renda em cursos de alta concorrência (PIOTTO, 2007). Assim, quando nos debruçamos sobre a trajetória de acesso e, sobretudo, quando consideramos a fruição dos recursos materiais e simbólicos propiciados pela universidade aos estudantes brasileiros de mais baixa renda, seja no setor público, seja no setor privado lucrativo (ALMEIDA, 2009; 2014), algumas questões para reflexão fazem-se decisivas.

Referente ao acesso, temos o fato de a escola pública não conseguir cumprir a grade curricular do ensino médio exigida na maioria dos exames vestibulares Brasil afora, o que sempre a colocou em desvantagem competitiva frente a algumas escolas de elite da rede privada de ensino. Caberia perguntar, no momento atual, no qual, por exemplo, a Universidade de São Paulo (USP) acaba de superar sua histórica resistência e aprovar a seleção de parte de suas vagas pelo Enem, ${ }^{7}$ se esse método de seleção não perderá seu diferencial em relação ao vestibular tradicional, transformando-se, paradoxalmente, naquilo que combatia quando foi pensado, no final da década de 1990. Em outras palavras, o vestibular como "catraca" ainda persiste entre nós, tragando até mesmo inovações que, de início, foram pensadas e materializadas na direção de uma seleção mais equânime e com maior respeito aos conteúdos desenvolvidos no ensino médio, sobretudo o público.

O desconhecimento e a falta de informação sobre caminhos possíveis para o ingresso nas universidades públicas e mesmo sobre programas como o ProUni e outras ações afirmativas, como cotas e bônus, constituem também um dos fatores que afasta o estudante de baixa renda do "sonho" de estudar nas instituições públicas de educação superior, notadamente naquelas de maior prestígio.

Outro aspecto volta-se para a discussão sobre a qualidade dos cursos e universidades que frequentam. Logo, além de poder ingressar na educação superior, é preciso também refletir sobre a efetividade social das carreiras a que os estudantes bolsistas do ProUni têm acesso. Contraintuitivamente, antes do ProUni e da expansão da Rede Pública Federal de Ensino Superior (Reuni), o setor público, de maior qualidade educacional, era mais socialmente permeável aos segmentos de baixa renda e de cor negra e parda. Dados de Sampaio, Limongi e Torres (2000) para os formandos do

7 Vale notar, contudo, que nem todas as faculdades e institutos aderiram, e o peso atribuído ao exame também varia conforme a decisão das congregações das unidades.

8 O termo aqui remete aos movimentos urbanos que problematizam as barreiras de acesso a espaços culturais ou públicos, ao introduzir uma lógica de seletividade e privatização. 
Provão já apontavam tal característica. Almeida (2009), em pesquisa com estudantes dos segmentos populares na USP, chegou à mesma conclusão "[...] antes do status de fazer parte da USP, é o aspecto financeiro, da gratuidade, que marca a escolha da universidade" (op. cit., p. 29).

Também a universidade pública mostra-se decisiva quando pensamos nas questões que ultrapassam a garantia do acesso, envolvendo a permanência no curso: ${ }^{9}$

[...] a população de baixa renda não necessita apenas de gratuidade integral ou parcial para estudar, mas de condições que apenas as instituições públicas, ainda, podem oferecer, tais como: transporte, moradia estudantil, alimentação subsidiada, assistência médica disponível nos hospitais universitários, bolsas de pesquisa, entre outros (CARVALHO, 2006, p. 16).

É precisamente aqui que temos o aspecto dilemático das políticas de inclusão no ensino superior no período que analisamos: o diferencial do ProUni é justamente ter possibilitado que indivíduos mais velhos, casados, com filhos, provedores de família e moradores de bairros periféricos pudessem acessar o ensino superior. Foi o programa que deu vez e voz no ensino superior a essa fração da classe trabalhadora. Contudo, a maioria desses mesmos bolsistas está alocada em cursos desclassificados, estigmatizados por uma série de aspectos inter-relacionados: faculdades desprestigiadas, formato curto do curso, baixa avaliação no Exame Nacional de Desempenho de Estudantes (Enade), baixo retorno financeiro, menor ou quase inexistente diferencial simbólico, estrutura precária, baixa percepção social da qualidade da formação obtida. Quando discutimos a escolha do curso, a fala de uma estudante de tecnologia em recursos humanos da Faculdade Sumaré, na cidade de São Paulo, sintetiza muitos relatos obtidos juntos aos pesquisados: "não foi minha primeira opção, foi a única" (ALMEIDA, 2013).

\section{Considerações finais}

Ao recuperar a trajetória da configuração do ensino superior no Brasil, destacamos seu caráter elitizado e as contradições inseridas quando do processo de democratização (relativa) do acesso a este nível de ensino. Ao delinear as novas configurações do mercado de trabalho e, em especial, dos circuitos do mercado de trabalho a que jovens das camadas populares parecem ter acesso (GUIMARÃES, 2013) ou, em sentido diverso, ao nos referirmos a estudos que sugerem que o acesso ao ensino superior tem sido realizado por trabalhadores, mais velhos, por vezes casados, e cujas ocupações não permitem entrever o "rendimento" dos anos

9 O ProUni dispõe de uma bolsa-permanência no valor de $\mathrm{R} \$ 300,00$ somente para os cursos integrais (entenda-se por isso o de Medicina). 
de escolarização, procuramos elementos para pensar os elos entre juventude, educação e trabalho, intensamente transformados nos últimos 30 anos.

Vimos, assim, que os "usos" do ensino superior por parte dos jovens de camadas populares que o acessam pela via de programas como o ProUni ou o Fies pouco têm a ver com a experiência dos jovens das camadas médias ou das elites: se estes têm no acesso ao ensino superior (em geral público ou, se privado, em escolas e cursos prestigiados) uma continuidade "natural" de sua trajetória, os primeiros reiteram a escolha do possível, orientando sua decisão por critérios pragmáticos. O diploma traz "recompensas" para além do rendimento - como vimos, muitas vezes parco no mercado de trabalho: seu significado reside em sua contribuição para sustentar, simbolicamente, o processo de mobilidade ascendente pela via do consumo que se abriu na última década, a partir do "lulismo" ou "pós-neoliberalismo" (FRENCH; FORTES, 2012; SINGER, 2012; JARDIM, 2013).

Trata-se, assim, das contradições geradas por um modelo de desenvolvimento econômico que, a despeito de seus inegáveis efeitos positivos sobre as seculares desigualdades brasileiras, encontra seus limites por não ter, justamente, enfrentado de modo mais profundo os mecanismos de produção e reprodução de uma estrutura ainda imensamente desigual. É assim que, frente a um mercado de trabalho escalonado em degraus tão altos, o acesso ao ensino superior cumpre mais uma função simbólica, do ponto de vista do trabalhador estudante, e seletiva, do ponto de vista das empresas contratantes, do que efetivamente resulta em acesso a postos de trabalho mais protegidos, melhor remunerados ou cujas competências demandadas relacionem-se à qualificação.

O espírito da questão que procuramos enfrentar neste artigo é bem captado por Passeron (1979, p. 44): "[...] retornar ao debate que se instaurou no início dos anos 1960 em torno do ensino superior dá a impressão desconcertante de um panorama profundamente transformado e, entretanto, rico de déjà-vu".

Enfrentar a complexidade da efetiva democratização do ensino superior é tarefa urgente, pois o quadro configurado pelas contradições internas à própria trajetória do sistema escolar, articuladas às transformações vividas no país nas últimas décadas no mundo do trabalho e das políticas sociais, é de difícil apreensão. Como negar a importância da chegada de segmentos populares ao nível superior? Como fazer a crítica da qualidade dos serviços educacionais privados a que tem acesso milhões de cidadãos, sem alternativa que não seja exclui-los desse nível de ensino - alternativa que, além disso, traz à tona as desigualdades escolares anteriores, pois atesta os limites da escolarização que puderam obter? Como refrear processos de inclusão, ainda que pela via do consumo de serviços educacionais, em nome de uma qualidade que talvez - por obra mesmo das contradições advindas da forma de expansão desde os anos 1960 - não seja possível massificar e, mais do que isso, não interesse a esses segmentos da população, ao menos não na mesma estrutura atual de ensino, 
pesquisa e extensão (a exemplo do que houve com a universalização da escola pública)?

Talvez, à semelhança de outras questões estruturais para a análise social, o tema da democratização, nesse sentido específico da ampliação de vagas e da inclusão de parcelas da população, não possa escapar desse tom de algo já visto, alterado e, no entanto, nunca superado (aliás, levado a novo patamar pelas transformações recentes). Esses processos de democratização, entre os quais o do ensino, jamais se realizam por completo e, aliás, resta inquirir até que ponto é possível sustenta-los em uma sociedade ainda tão marcada por profundas desigualdades, tal como a nossa.

\section{Referências}

ABDAL, A.; NAVARRA, J. Uni por Uni, eu escolhi a que era do lado da minha casa: deslocamentos cotidianos e o acesso, a permanência e a fruição da universidade por bolsistas do ProUni no ensino superior privado. Novos Estudos, São Paulo, n. 99, p. 65-87, 2014.

ALMEIDA, W. M. USP para todos? Estudantes com desvantagens socioeconômicas e educacionais e fruição da universidade pública. São Paulo: Musa Editora, 2009.

. ProUni e o ensino superior privado lucrativo em São Paulo: uma análise sociológica. São Paulo: Musa Editora, 2014.

BARBOSA, M. A. Estudantes de classes pobres na universidade pública: um estudo de depoimentos em psicologia social. 2004. Dissertação (Mestrado em Psicologia). Universidade de São Paulo, São Paulo, 2004.

BEISIEGEL, C. R. Educação e sociedade no Brasil após 1930. In: FAUSTO, B. (Org.). História geral da civilização brasileira: o Brasil republicano. São Paulo: Difel, 1986. v. 4.

BERNARDI, B. B. O conceito de dependência da trajetória (path dependence): definições e controvérsias teóricas. Perspectivas, São Paulo, v. 41, p. 137-167, 2012.

BOURDIEU, P.; PASSERON, J.-C. Les héritiers: les étudiants e la culture. Paris: Minuit, 1964.

. La reproduction: éléments pour une théorie du systeme d'enseignement. Paris: Minuit, 1970.

CARVALHO, C. H. A. O ProUni no governo Lula e o jogo político em torno do 
acesso ao ensino superior. Educação e Sociedade, Campinas, v. 27, n. 96, p. 9791000, 2006.

CATANI, A. M.; GILIOLI, R. S. P. O ProUni na encruzilhada: entre a cidadania e a privatização. Linhas Críticas, Brasília, v. 11, n. 20, p. 55-68, 2005.

COMIN, A.; BARBOSA, R. J. Trabalhar para estudar. Sobre a pertinência da noção de transição escola-trabalho no Brasil. Novos Estudos, São Paulo, n. 91, p. 75-95, 2011.

CUNHA, L. A. A expansão do ensino superior: causas e consequências. Debate e Crítica, n. 5, p. 27-58, 1975.

D'ANDREA, T. A formação dos sujeitos periféricos: cultura e política na periferia de São Paulo. 2013. Tese (Doutorado em Sociologia) - Universidade de São Paulo, São Paulo, 2013.

DAUSTER, T. Uma revolução silenciosa: notas sobre o ingresso de setores de baixa renda na universidade. In: ENCONTRO ANUAL DA ANPOCS, 27., 2003, Caxambu. Anais... Caxambu: Anpocs, 2003.

DRAIBE, S. O welfare state no Brasil: características e perspectivas. Campinas: Unicamp, 1993. (Caderno de Pesquisa, n. 8).

DURHAM, E. R. O ensino superior privado no Brasil: público e privado. São Paulo: Nupes, 2003. (Documentos de Trabalho, n. 3/03).

ESPING-ANDERSEN, G. Three worlds of welfare capitalism. In: PIERSON, P.; CASTLES, F. G. (Eds.). The welfare state reader. 2nd ed. Great Britain: Polity Press, 2006.

FRENCH, J.; FORTES, A. A "era Lula", as eleições presidenciais de 2010 e os desafios do pós-neoliberalismo. Tempo Social, São Paulo, v. 24, n. 1, p. 201-228, 2012.

GOUVEIA, A. J. Democratização do ensino superior. Revista Brasileira de Estudos Pedagógicos, v. 50, n. 112, p. 232-44, 1968.

GUIMARÃES, A. S. Cidadania e retóricas negras de inclusão social. Lua Nova, São Paulo, n. 85, p. 13-40, 2012.

GUIMARÃES, N. A. Trajetórias juvenis: um novo nicho em meio à expansão das oportunidades de trabalho? In: MACAMBIRA, J.; ANDRADE, F. R. B. (Orgs.). Trabalho e formação profissional: juventudes em transição. Fortaleza: IDT; Uece; BNB, 2013.

HILSDORF, M. L. S. História da educação brasileira: leituras. São Paulo: Thomson, 
2006.

JARDIM, F. A. A. Entre desalento e invenção: experiência de desemprego e desenraizamento em São Paulo. São Paulo: Annablume, 2009.

As persistências das desigualdades e gestão das diferenças na América Latina "pós-neoliberal". In: CONGRESSO ALAS - CRISE E EMERGÊNCIAS SOCIAIS NA AMÉRICA LATINA, 29., 2013, Santiago. Anais... Santiago: Alas, 2013. Disponível em: <actacientifica.servicioit.cl/biblioteca/gt/GT8/GT8_JardimA.pdf>.

KERSTENETZKY, C.L.; UCHÔA, C. Moradia inadequada, escolaridade insuficiente, crédito limitado: em busca da nova classe média. In: BARTELT, D. (org.) A "nova classe média" no Brasil como conceito e projeto político. Rio de Janeiro: Fundação Heinrich Böll, 2013.

LIMA, H. I.; SILVA, B. R. G.; SILVA, P. R. Recuperando a história do acesso ao ensino superior (1911-1925). Ensaio: Avaliação e Políticas Públicas em Educação, Rio de Janeiro, v. 10, n. 37, p. 441-456, 2002.

MARSHALL, T. H. Cidadania, classe e status social. Rio de Janeiro: Zahar, 1978.

MARTINS, C. B. A Reforma Universitária de 1968 e a abertura para o ensino superior privado no Brasil. Educação \& Sociedade, Campinas, v. 30, n. 106, p. 1535, 2009.

MOEHLECKE, S. Fronteiras da Igualdade no ensino superior: excelência \& justiça racial. 2004. Tese (Doutorado em Educação) - Universidade de São Paulo, São Paulo, 2004.

OLIVEIRA, R. P. Da universalização do ensino fundamental ao desafio da qualidade: uma análise histórica. Educação \& Sociedade, Campinas, v. 28, n. 100, p. 661-690, 2007.

OLIVEN, A. C. Arquipélago de competência: universidades brasileiras na década de 90. Cadernos de Pesquisa, São Paulo, n. 86, p. 75-78, ago. 1993.

PAVÃO, A. Inclusão e exclusão das camadas populares na universidade: o papel da leitura e da escrita. 2004. Tese (Doutorado) - Pontifícia Universidade Católica do Rio de Janeiro (PUC-Rio), Rio de Janeiro, 2004.

PIOTTO, D. C. As exceções e suas regras: estudantes das camadas populares em uma universidade pública. 2007. Tese (Doutorado em Psicologia) - Universidade de São Paulo, São Paulo, 2007.

ROSENBURG, C. Nota alta: a educação já movimenta 90 bilhões de reais por ano no Brasil e deve ser o setor que mais crescerá no mundo nas próximas décadas. 
Exame, n. 7, p. 35-45, abr. 2002.

SABOIA, J. Baixo crescimento econômico e melhora do mercado de trabalho como entender a aparente contradição? Estudos Avançados, São Paulo, v. 28, n. 81, p. 115-125, 2014.

SAMPAIO, H. O ensino superior no Brasil: o setor privado. São Paulo: Hucitec; Fapesp, 2000.

SAMPAIO, H.; LIMONGI, F.; TORRES, H. Equidade e heterogeneidade no ensino superior brasileiro. Brasília: Inep, 2000.

SANTOS, C. M. O acesso ao ensino superior no Brasil: a questão da elitização. Ensaio, Rio de Janeiro, v. 6, n. 19, p. 237-258, 1998.

SCHOFER, E.; MEYER, J. W. The worldwide expansion of higher education in twentieth century. American Sociological Review, v. 70, p. 898-920, Dec. 2005.

SILVA, J. Por que uns e não outros? Caminhada de jovens pobres para a universidade. Rio de Janeiro: Sette Letras, 2003.

SINGER, A. Os sentidos do lulismo: reforma gradual e pacto conservador. São Paulo: Companhia das Letras, 2012.

SOUZA, P.R. A revolução gerenciada: educação no Brasil (1995-2002). São Paulo: Prentice Hall, 2005.

SOUZA, J. Os batalhadores brasileiros: nova classe média ou nova classe trabalhadora? Belo Horizonte: Editora UFMG, 2012.

TROGER, V. Bourdieu et l'école: la démocratisation désenchantée. Sciences Humaines, n.15, fev.-mar., p. 16-23, 2012.

VILLAS BÔAS, G. Seleção e partilha: excelência e desigualdades sociais na universidade. Teoria \& Sociedade, n. 7, p. 95-115, jun. 2001. 
Recebido em julho de 2015.

Aprovado em outubro de 2015.

Wilson Mesquita de Almeida é doutor em Sociologia pela Universidade de São Paulo (USP) e professor do Centro de Engenharia, Modelagem e Ciências Sociais Aplicadas da Universidade Federal do ABC (UFABC). E-mail: <wilson.mesquita@ ufabc.edu.br>.

Fabiana Augusta Alves Jardim é doutora em Sociologia pela Universidade de São Paulo (USP) e professora do Departamento de Filosofia da Educação e Ciências da Educação da Faculdade de Educação da USP. E-mail: <fajardim@usp.br>. 